\title{
Public's Attitudes Toward Health Information on Twitter: A Cross-sectional Survey Based on the Saudi Population
}

\author{
Shareefah A. Alassiri ${ }^{1}$, Areej S. Alowfi ${ }^{2}$ \\ 1. Administration of Public Health, Ministry of Health, Jeddah, SAU 2 . Family Medicine, King Saud Bin Abdulaziz \\ University for Health Sciences / King Abdulaziz Medical City, Ministry of National Guard Health Affairs, Jeddah, SAU
}

Corresponding author: Shareefah A. Alassiri, shaalassiri@gmail.com

\begin{abstract}
Health information dissemination through social media networks has transformed the process of communication between health practitioners, patients, and the public. Twitter is one of the most commonly used social media networks in Saudi Arabia for sharing health information. However, the reliability of health information on Twitter has been questioned by some skeptics, thereby placing the public at a significant health risk. This study was conducted to assess the attitudes of the general population of Saudi Arabia towards health information sought from Twitter. Of the 384 total respondents, 199 (51.8\%) considered using Twitter as a source of health information as a positive experience due to its ease of use and the accessibility of information $(131,66.0 \%)$. The study found that respondents have great concern about nutrition/weight loss (229, 59.6\%), healthy lifestyle (225, 58.6\%), and getting a better understanding of health care misconceptions (168, 43\%). Most of the respondents (167, 43.5\%) were satisfied using Twitter as a source of health information. However, a few respondents experienced harm to their health as a result of false medical advice $(2,0.5 \%)$ and false health information (2, 0.5\%) they found on Twitter. This study concludes that Twitter is mainly useful in obtaining health knowledge for maintaining good health, preventing illness, and curing illnesses or diseases. However, the public must take extra caution when obtaining health information from Twitter. It is essential for Twitter users seeking medical information to also seek professional medical advice or consultation, as necessary, to prevent a significant health risk.
\end{abstract}

Received 10/02/2019

Review began 10/02/2019 Review ended 10/07/2019 Published 10/08/2019

() Copyright 2019

Alassiri et al. This is an open access article distributed under the terms of the Creative Commons Attribution License CC-BY 3.0., which permits unrestricted use, distribution, and reproduction in any medium, provided the original author and source are credited.
Categories: Family/General Practice, Public Health, Healthcare Technology

Keywords: twitter, health information, saudi arabia

\section{Introduction}

The dissemination of health information during this digital generation has emerged in various ways to convey messages to the target population or audience. Social media network sites and the availability of web-based platforms that facilitate information sharing in the form of user-generated content have indeed transformed the process of communication.

According to the Internet Live Stats website, $40 \%$ of today's world population has an Internet connection [1]. In addition, the unprecedented number of people using smartphones for social and digital media provides an opportunity for health practitioners and institutions to communicate and disseminate health information among individuals and to the public concerning health care issues [2].

A survey of 111 patients from an outpatient family practice clinic in southern Utah, United States, showed that $56 \%$ wished that their physicians should use social networking platforms for health information sharing, answering general questions, setting appointments and reminders, notifying prescriptions, and reporting diagnostic test results [3].

Physicians are currently exploring social media network platforms as a way to seamlessly share health information with relevant health care stakeholders. For instance, social networks are being utilized to seek and share health information, to be a source of communication with trainees and colleagues, to market physicians' practices, to disseminate research, and to spread health recommendations. Moreover, direct interaction with patients has been growing through the use of social media networks [4-6]. However, skeptics may argue about the efficiency and safety of using Twitter as a social media networking tool in gaining health information for the public and for medical and allied health professionals [7].

Therefore, this study aims to assess the attitudes of the general population of Saudi Arabia towards seeking health information through Twitter.

\section{Materials And Methods}

This is a cross-sectional study conducted among Twitter users in Saudi Arabia to determine their attitudes 
towards seeking health information on Twitter as a medium of information. Inclusion criteria in the selection of the respondents were: Twitter users living in Saudi Arabia (i.e., Saudi and non-Saudi nationals), at least 18 years of age, and those who used Twitter to search and/or seek health information. The minimum sample size was estimated to be 385 using the online Raosoft Inc. sample size calculator (WA, US) [8] based on the total number of Twitter users in Saudi Arabia (i.e., approximately 5 million) [9] and with an acceptable margin of error of $5 \%$ and a confidence level of $95 \%$.

The researchers designed a self-administered survey questionnaire in the English and Arabic languages. Two family medicine consultants who are native Arabic speakers validated the questionnaire for the construct, content, and face validity. The survey questionnaire consisted of four parts: questions pertaining to the respondents' sociodemographic data, respondents' characteristics as a Twitter user, health-related benefits and harms from seeking health information from Twitter, and reasons for using Twitter to search for health information. A pilot test was conducted twice (i.e., an initial pilot survey and a follow-up survey after one week) to 20 randomly selected Twitter users who volunteered to test for internal consistency (Cronbach's alpha 0.89 ) and the test-retest reliability (alpha 0.80) of the questionnaire. The final survey questionnaire was distributed using the exponential non-discriminative snowball sampling technique. A survey link posted as a tweet by the researchers and shared among Twitter users with different traits or demographic characteristics as strata to reach out to a greater number of the Saudi population. The survey link directed respondents towards the SurveyMonkey platform with an option to change the language based on the preferred language of the respondents. Respondents consented to participate by submitting the completed survey questionnaire. The survey was conducted from June 7, 2016, to June 30, 2016. All collected data about the respondents were stringently maintained to be anonymous and confidential throughout the study.

All collected data were analyzed using the Statistical Package for the Social Sciences software, version 21 (SPSS v.21; IBM Corp, Armonk, NY, US). Frequency and percentage were used for describing categorical data. The chi-square test $(\chi 2)$ was used to test for the association between categorical variables. A p-value of $\leqslant$ 0.05 was considered significant.

Permission to conduct the study was obtained from the Department of Research and Ethics Committee and the Program Director of Family Medicine of Prince Sultan Military Medical Center, Riyadh, Saudi Arabia, before commencing the study, with the supervision of the Joint Program of Family and Community Medicine.

\section{Results}

Of the 401 respondents who participated in the survey, 384 (95.76\%) fulfilled the inclusion criteria and were included in the final analysis. Most respondents were aged 18 to 35 years $(309,80.5 \%)$ and most were male (242, 63.0\%). There were 360 (93.8\%) who were Saudi nationals and 24 (6.2\%) who were non-Saudi nationals. There were 198 (51.6\%) from the region of Makkah, and there were 234 (60.9\%) who had tertiary education. The majority, 129 (33.6\%), worked in the medical field, followed by 78 (20.3\%) students. There were 224 (58.4\%) respondents who reported a monthly income of more than 12,000 Saudi Riyals (i.e., US\$ 3,200 or $€ 2,925)$. Table 1 presents the complete socio-demographic characteristics of the respondents.

\begin{tabular}{|c|c|c|c|}
\hline \multicolumn{2}{|c|}{ Socio-demographic characteristics } & Frequency (n) & Percentage (\%) \\
\hline \multirow{4}{*}{ Age } & $18-25$ & 142 & 37.0 \\
\hline & $26-35$ & 167 & 43.5 \\
\hline & $36-45$ & 47 & 12.2 \\
\hline & $>45$ & 28 & 7.3 \\
\hline \multirow[t]{2}{*}{ Gender } & Male & 242 & 63.0 \\
\hline & Female & 142 & 37.0 \\
\hline \multirow[t]{2}{*}{ Nationality } & Saudi & 360 & 93.8 \\
\hline & Non-Saudi & 24 & 6.2 \\
\hline \multirow[t]{4}{*}{ Marital Status } & Single & 200 & 52.1 \\
\hline & Married & 178 & 46.4 \\
\hline & Divorced & 6 & 1.5 \\
\hline & Widow & 0 & 0.0 \\
\hline Region & Makkah & 198 & 51.6 \\
\hline
\end{tabular}




\section{Cureus}

\begin{tabular}{|c|c|c|c|}
\hline & Riyadh & 87 & 22.7 \\
\hline & Assir & 45 & 11.7 \\
\hline & Madinah & 24 & 6.2 \\
\hline & Jazan & 5 & 1.3 \\
\hline & Eastern Region & 5 & 1.3 \\
\hline & Others & 20 & 5.2 \\
\hline Educational Attainment & Intermediate & 8 & 2.1 \\
\hline & Secondary & 49 & 12.8 \\
\hline & University & 234 & 60.9 \\
\hline & Diploma & 22 & 5.7 \\
\hline & Masters & 47 & 12.2 \\
\hline & Doctorate & 24 & 6.3 \\
\hline Field of Occupation & Unemployed & 52 & 13.5 \\
\hline & Student & 78 & 20.3 \\
\hline & Medical & 129 & 33.6 \\
\hline & Educational & 38 & 9.9 \\
\hline & Engineering & 7 & 1.8 \\
\hline & Administration & 35 & 9.1 \\
\hline & Business & 14 & 3.6 \\
\hline & Retired & 8 & 2.1 \\
\hline & Other & 23 & 6.1 \\
\hline Monthly Income (Saudi Riyals) & $\leq 1000$ & 4 & 1.0 \\
\hline & $1001-3000$ & 28 & 7.3 \\
\hline & $3001-6000$ & 28 & 7.3 \\
\hline & $6001-9000$ & 37 & 9.6 \\
\hline & $9001-12,000$ & 63 & 16.4 \\
\hline & $>12,000$ & 224 & 58.4 \\
\hline
\end{tabular}

\section{TABLE 1: Socio-demographic characteristics of the respondents}

Most of the respondents have a Twitter user for one to five years (283, 73.6\%). The majority of respondents have a positive response $(199,51.8 \%)$ to using Twitter as a source of health information, compared to a negative response $(185,48.2 \%)$. Moreover, most of the respondents $(131,66.0 \%)$ preferred Twitter due to its ease of use and access. Respondents have mostly sought information about physicians (139, 36.2\%) and government health institutions (105, 27.3\%). Table 2 shows the characteristics of respondents who use Twitter to obtain health information. 


\section{Cureus}

\begin{tabular}{|c|c|c|}
\hline Characteristics of respondents who use Twitter & Frequency (n) & Percentage (\%) \\
\hline \multicolumn{3}{|l|}{ Duration of Twitter use } \\
\hline$<1$ year & 29 & 7.6 \\
\hline $1-3$ years & 106 & 27.5 \\
\hline 4-5 years & 177 & 46.1 \\
\hline$>5$ years & 72 & 18.8 \\
\hline \multicolumn{3}{|l|}{ Preference of I witter use for health information } \\
\hline Positive & 199 & 51.8 \\
\hline Negative & 185 & 48.2 \\
\hline \multicolumn{3}{|l|}{ Reason for preference } \\
\hline Ease of use and access & 131 & 66.0 \\
\hline Comprehensive information & 32 & 16.0 \\
\hline Validity of information & 10 & 5.0 \\
\hline Low cost & 15 & 7.5 \\
\hline Other & 11 & 5.5 \\
\hline \multicolumn{3}{|c|}{ Seeking health information through accounts belonging to: } \\
\hline Governmental health institutions & 105 & 27.3 \\
\hline Private health institutions & 15 & 3.9 \\
\hline Medical organizations & 43 & 11.2 \\
\hline Health campaigns & 27 & 7.1 \\
\hline Particular physicians & 139 & 36.2 \\
\hline Particular specialty search & 19 & 4.9 \\
\hline Other & 36 & 9.4 \\
\hline
\end{tabular}

\section{TABLE 2: Characteristics of respondents who use Twitter to obtain health information}

As shown in Table 3, most respondents said that using Twitter to obtain health information will provide a better understanding of misconceptions $(168,43 \%)$. They also used Twitter mainly to search for general knowledge $(256,66.7 \%)$, disease prevention $(170,44.3 \%)$, and cures to illness $(154,40.1 \%)$. Of the searched health specialties on Twitter, nutrition $(229,59.6 \%)$ and healthy lifestyle $(225,58.6 \%)$ were the most searched items. Reasons for seeking health information in a particular medical specialty are shown in Table 4. 


\section{Cureus}

Benefits from Twitter use

Better diet

Abstinence from smoking

94

Weight loss

Better health care for my family

Better understanding of misconceptions

Other

Level of satisfaction of obtaining health information through Twitter

Very satisfactory

Satisfactory

Neutral

Unsatisfactory

Distribution of respondents who experienced harm caused by false health information on Twitter

A harm experience

Don't know

The harm caused by the application of information obtained from Twitter

Pain in teeth implant

Severe dizziness

Visited the hospital due to harm from the application of information obtained from Twitter

Yes

Never
312

70

0.05

1

0.05

TABLE 3: Benefits and harms of obtaining health information through Twitter 


\section{Cureus}

\begin{tabular}{|c|c|c|}
\hline Items & Frequency $(\mathbf{n})$ & Percentage (\%) \\
\hline \multicolumn{3}{|l|}{ Reasons for Twitter search } \\
\hline Disease prevention & 170 & 44.3 \\
\hline Search of a cure for my illness & 154 & 40.1 \\
\hline Epidemic outbreaks & 109 & 28.4 \\
\hline General knowledge & 256 & 66.7 \\
\hline \multicolumn{3}{|c|}{ Twitter search according to health specialties } \\
\hline Nutrition/weight loss & 229 & 59.6 \\
\hline Healthy lifestyle & 225 & 58.6 \\
\hline Family medicine & 125 & 32.6 \\
\hline Cosmetics & 90 & 23.4 \\
\hline Cancer and its prevention & 75 & 19.5 \\
\hline Dermatology & 61 & 15.9 \\
\hline First aid & 61 & 15.9 \\
\hline Dental & 59 & 15.4 \\
\hline Internal medicine & 56 & 14.6 \\
\hline Pediatrics & 44 & 11.5 \\
\hline Ob-Gyne & 43 & 11.2 \\
\hline Other & 43 & 11.2 \\
\hline Infectious diseases & 39 & 10.2 \\
\hline Heart diseases & 36 & 9.4 \\
\hline Sexually transmitted diseases & 28 & 7.3 \\
\hline Pulmonology & 26 & 6.8 \\
\hline
\end{tabular}

\section{TABLE 4: Reasons for searching health information on Twitter}

Table 5 shows that the age group of $18-25$ (144, 37.5\%) and 26-35 (166, 43.2\%) and the benefits gained from seeking health information on Twitter were all statistically significant $(\mathrm{p}=0.01)$. Lastly, professionals in the medical field (129, 33.6\%) have experienced favorable benefits from Twitter as compared to other occupations. The correlation between the benefits gained from Twitter use and the respondents' occupation show statistical significance $(\mathrm{p}<0.001)$ (Table 6$)$. 


\section{Cureus}

\begin{tabular}{|c|c|c|c|c|c|}
\hline \multirow{2}{*}{ Benefits from Twitter use } & \multicolumn{4}{|c|}{ Age Group } & \multirow{2}{*}{ P-Value } \\
\hline & $18-25$ & $26-35$ & $36-45$ & $>45$ & \\
\hline Better diet & 45 & 33 & 8 & 8 & \multirow{6}{*}{0.01} \\
\hline Abstinence from smoking & 0 & 4 & 0 & 0 & \\
\hline Weight loss & 13 & 18 & 7 & 1 & \\
\hline Better health care for my family & 6 & 17 & 7 & 0 & \\
\hline Better understanding of misconceptions & 71 & 66 & 18 & 13 & \\
\hline Other & 9 & 28 & 7 & 6 & \\
\hline
\end{tabular}

TABLE 5: Association between the benefits of Twitter use and age group

\begin{tabular}{|c|c|c|c|c|c|c|c|}
\hline \multirow{2}{*}{$\begin{array}{l}\text { Occupational } \\
\text { field }\end{array}$} & \multicolumn{6}{|c|}{ Benefits from Twitter use } & \multirow{2}{*}{$\begin{array}{l}\text { P- } \\
\text { Value }\end{array}$} \\
\hline & $\begin{array}{l}\text { Better } \\
\text { diet }\end{array}$ & $\begin{array}{l}\text { Abstinence from } \\
\text { smoking }\end{array}$ & $\begin{array}{l}\text { Weight } \\
\text { loss }\end{array}$ & $\begin{array}{l}\text { Better health care for } \\
\text { family }\end{array}$ & $\begin{array}{l}\text { Better understanding of } \\
\text { misconceptions }\end{array}$ & Other & \\
\hline Unemployed & 14 & 0 & 2 & 2 & 31 & 3 & \multirow{9}{*}{$\begin{array}{l}< \\
0.001\end{array}$} \\
\hline Student & 23 & 0 & 0 & 2 & 8 & 6 & \\
\hline Medical & 24 & 2 & 13 & 15 & 47 & 28 & \\
\hline Educational & 10 & 2 & 5 & 1 & 20 & 0 & \\
\hline Engineering & 1 & 0 & 3 & 0 & 0 & 3 & \\
\hline Administration & 9 & 0 & 4 & 7 & 14 & 1 & \\
\hline Business & 4 & 0 & 0 & 2 & 8 & 0 & \\
\hline Retired & 2 & 0 & 4 & 0 & 3 & 3 & \\
\hline Other & 7 & 0 & 4 & 1 & 6 & 5 & \\
\hline
\end{tabular}

TABLE 6: Relationship between the benefits of Twitter use and the respondents' occupational field

\section{Discussion}

As a growing proportion of individuals seek health information online and through social media platforms, communication about health has become increasingly interactive and dynamic. Twitter is one of the most commonly used social media platforms due to its popularity among the global audience, easy access to information, and a medium that quickly spreads information [10]. The results of this study show an increase in the number of Twitter users in Saudi Arabia who seek health information, as more than half $(131,51.8 \%)$ of the respondents preferred Twitter as a source of health information due to its ease of use and accessibility. With this widespread popularity of Twitter come new challenges in the aspects of communication and learning about health information across users of different age groups [11].

Nowadays, the dissemination of health information on diseases and treatment is almost entirely through social media. Twitter, for instance, has been shown to be an effective platform in the dissemination of information [12]. In the current study, more than half of the respondents $(199,51.8 \%)$ expressed a positive attitude towards the use of Twitter to search for health-related information. As evidence, 256 (66.7\%) of the respondents used Twitter to obtain general knowledge, perhaps because most of the respondents of this study were from the medical field.

Chew et al. conducted a study on the dissemination of health information through Twitter. They reviewed Twitter status on antibiotics updates, determined the overarching categories, and explored evidence of misunderstanding or misuse of antibiotics. The study concluded that social media offered a means of health 
information sharing. However, further research was suggested to determine the misunderstanding or misuse of antibiotics among Twitter users. Thus, to disseminate valid information, promote positive behavior change among Twitter users, and explore how Twitter can be used as a tool to gather real-time health data [13]. This result is similar to what the current study results imply. Although most of the respondents expressed a positive attitude $(199,51.8 \%)$ towards Twitter use particularly in the aspect of nutrition (229, $59.6 \%)$ and healthy lifestyles $(225,58.6 \%)$, this study found that most of the respondents $(281,73.2 \%)$ doubted the credibility of the information available on Twitter.

In the study of Brady et al., the use of Twitter had demonstrated a measurable impact on strengthening the collaboration among physicians. Enriching their ability to communicate and share ideas with one another effectively and to bring issues need to be discussed [14]. A recent study verified over 2,000 doctors on Twitter based on their National Provider Identifier. These doctors have at least 300 followers each and tweet more than once per day [15]. The results of the current study showed that more than one-third of respondents (139, 36.2\%) sought health information through accounts belonging to physicians.

The accuracy of health information is one of the major concerns for Twitter users. Chretien et al. studied the prevalence of misinformation in tweets about health care, and the results revealed that about $20 \%$ contained inaccurate information. The study also stressed the lack of a systematic process for misinformation checking on Twitter [16]. Choo et al. also agreed that it is quite easy for a non-expert to present their opinions as facts and appear to be credible as an unbiased medical professional [17].

The findings of the current study were aligned with those of the studies mentioned above. When the respondents asked if the health information they obtained from Twitter had met their needs, half of the respondents were satisfied (very satisfactory: $25,41.9 \%$; satisfactory: $167,43.5 \%$ ) and a few were unsatisfied (31, 8.1\%). Two respondents $(0.5 \%)$ claimed that they were harmed due to following the false health advice they received on Twitter. Another two respondents (0.5\%) claimed that they needed to visit a hospital as a result of following the false health information from Twitter (Table 3). Therefore, these findings must spur Twitter users to validate the credibility of health information they get from Twitter or, better yet, to seek professional medical advice to avoid similar circumstances.

The data analyzed in this study were based on the total number of respondents who voluntarily participated and completed the survey questionnaire. Since the majority of the respondents who participated were from medical backgrounds while there was a relatively low sample size in other occupational fields, the multiple variable analysis would be at risk of bias from multiple comparisons. However, based on the results of the study, we recommend conducting further research focusing on a non-medical background population to improve the generalization of this study's results. The reliability of health information on Twitter noticed by the respondents was based on their own understanding. Researchers did not assess the content of health information and the credibility of sources.

\section{Conclusions}

Searching for health information through Twitter is increasing among the population of Saudi Arabia. The health information on Twitter is somewhat questionable for some of the respondents, and some had experienced harm due to false health advice and information. On this matter, the public must be extra cautious of all health information obtained from Twitter. Moreover, it is essential for Twitter users to seek professional medical advice or consultation, as necessary, to prevent a significant health risk.

\section{Additional Information \\ Disclosures}

Human subjects: Consent was obtained by all participants in this study. Research Ethics Committee of Prince Sultan Military Medical City issued approval HAP-01-R-015. Animal subjects: All authors have confirmed that this study did not involve animal subjects or tissue. Conflicts of interest: In compliance with the ICMJE uniform disclosure form, all authors declare the following: Payment/services info: All authors have declared that no financial support was received from any organization for the submitted work. Financial relationships: All authors have declared that they have no financial relationships at present or within the previous three years with any organizations that might have an interest in the submitted work. Other relationships: All authors have declared that there are no other relationships or activities that could appear to have influenced the submitted work.

\section{References}

1. Internet users in the world. (2017). Accessed: August 7, 2017: http://www.internetlivestats.com.

2. Guseh JS II, Brendel RW, Brendel DH: Medical professionalism in the age of online social networking . J Med Ethics. 2009, 35:584-586. 10.1136/jme.2009.029231

3. Fisher J, Clayton M: Who gives a tweet: assessing patients' interest in the use of social media for health care. Worldviews Evid Based Nurs. 2012, 9:100-108. 10.1111/j.1741-6787.2012.00243.x

4. Should healthcare organizations use social media? . (2011). Accessed: June 27, 2017: https://www.slideshare.net/blueeyepathrec/should-healthcare-organizations-use-social-media. 


\section{Cureus}

5. Chretien KC, Farnan JM, Greysen SR, et al.: To friend or not to friend? Social networking and faculty perceptions of online professionalism. Acad Med. 2011, 86:1545-1550. 10.1097/ACM.0b013e3182356128

6. Kind T, Greysen SR, Chretien KC: Pediatric clerkship directors' social networking use and perceptions of online professionalism. Acad Pediatr. 2012, 12:142-148. 10.1016/j.acap.2011.12.003

7. Peer-to-peer health care (2013). Accessed: June 17, 2017: http://www.pewinternet.org/2013/01/15/peer-topeer-health-care/.

8. Raosoft sample size calculator. (2004). Accessed: June 27, 2017: http://www.raosoft.com/samplesize.html.

9. Number of Twitter users in Saudi Arabia from 2014 to 2016 . (2016). Accessed: February 1, 2017 : https://www.statista.com/statistics/558404/number-of-Twitter-users-in-saudi-arabia/ .

10. Robillard JM, Johnson TW, Hennessey C, et al.: Aging 2.0: health information about dementia on Twitter . PLoS One. 2013, 8:10.1371/journal.pone.0069861

11. Cain J: Social media in health care: the case for organizational policy and employee education . Am J Health Syst Pharm. 2011, 68:1036-1040. 10.2146/ajhp100589

12. Vance K, Howe W, Dellavalle RP: Social Internet sites as a source of public health information . Dermatol Clin. 2009, 27:133-136. 10.1016/j.det.2008.11.010

13. Chew C, Eysenbach G: Pandemics in the age of Twitter: content analysis of tweets during the 2009 H1N1 outbreak. PloS One. 2009, 1:2010-2015. 10.1371/journal.pone.0014118

14. Brady RRW, Chapman SJ, Atallah S, Chand M, Mayol J, Lacy AM, Wexner SD: \#colorectalsurgery. Br J Surg. 2017, 104:1470-1476. 10.1002/bis.10615

15. Choi M: Social media in clinical practice. Healthcare Inform Res. 2015, 21:138-140. 10.4258/hir.2015.21.2.138

16. Chretien K, Azar J, Kind T: Physicians on Twitter. JAMA. 2011, 305:566-568.

17. Choo EK, Ranney ML, Chan TM, et al.: Twitter as a tool for communication and knowledge exchange in academic medicine: A guide for skeptics and novices. Med Teach. 2015, 37:411-416. 10.3109/0142159x.2014.99337 